\title{
Role of low dose ecosprin and heparin in achieving live births in pregnancy with thrombophilia
}

\author{
Shilpa Asthana ${ }^{1 *}$, Bandana Sodhi², Satish Kumar ${ }^{3}$ \\ ${ }^{1}$ Department of Obstetrics and Gynecology, INHS Asvini, Mumbai, Maharashtra, India \\ ${ }^{2}$ Department of Obstetrics and Gynecology, Moolchand Medcity, Lajpat Nagar III, New Delhi, India \\ ${ }^{3}$ Department of Pathology and Blood Tranfusion, Armed Forces Transfusion Centre, Delhi Cant., New Delhi, India
}

Received: 21 October 2017

Accepted: 27 October 2017

\author{
*Correspondence: \\ Dr. Shilpa Asthana, \\ E-mail: asthanashilpa@gmail.com
}

Copyright: () the author(s), publisher and licensee Medip Academy. This is an open-access article distributed under the terms of the Creative Commons Attribution Non-Commercial License, which permits unrestricted non-commercial use, distribution, and reproduction in any medium, provided the original work is properly cited.

\begin{abstract}
Background: Thrombophilia is a disorder of haemostatic system that results in increased tendency of thrombus formation in both venous and arterial vascular system. The thrombotic events are not only restricted to venous thromboembolism but also can cause fetal loss (abortions or recurrent abortions and fetal demise), placental abruption, intrauterine growth restriction and severe pre-eclampsia. This study evaluates the role of administering thromboprophylaxis with heparin and ecosprin to patients with thrombophilia in pregnancy with previous history of adverse obstetric outcomes.

Methods: This prospective study was conducted in 60 patients diagnosed with thrombophilia during pregnancy. The objective of the study was to determine the role of administering low dose ecosprin and heparin as thromboprophylaxis in achieving live births in these patients with thrombophilia. All patients included in this study were prophylactically administered low dose ecosprin with either unfractionated heparin (5000 IU s.c, BD) or low molecular weight heparin (40 mg s.c, OD) during pregnancy. Patients were followed up in the antenatal period and the obstetric outcome noted. Comparisons were made between the obstetric outcomes of these patients receiving the aforesaid thromboprophylaxis with those of previous untreated pregnancies during which no ecosprin or heparin had been administered. The data obtained were subjected to statistical analysis using Students ' $\mathrm{t}$ ' test and Chi square analysis. $\mathrm{P}$ value $<0.05$ was considered statistically significant.

Results: Fifty nine of the sixty patients with thrombophilia and previous adverse pregnancy outcome who received prophylaxis with ecosprin and heparin during the present pregnancy had live births $(98.33 \%$; p <0.0001). Fifty-eight $(96.66 \%)$ of these patients progressed to term delivery and one $(1.67 \%)$ pregnancy resulted in a pre-term birth.

Conclusions: Present study reveals that prophylaxis with low dose ecosprin and heparin administered to patients with thrombophilia (acquired or inherited) with history of previous adverse obstetric outcome resulted in a positive outcome in terms of a significantly higher number of live births. However, larger studies are needed to further elaborate on the role of thromboprophylaxis in pregnancies with inherited thrombophilia.
\end{abstract}

Keywords: Adverse pregnancy outcome, Anti-phospholipid antibody syndrome, Thrombophilia - Inherited and Acquired, Maternal thrombophilia, Recurrent pregnancy loss, Thromboprophylaxis

\section{INTRODUCTION}

Thrombophilia is a disorder of haemostatic system that results in increased tendency of thrombus formation in both venous and arterial vascular system. The thrombotic events are not only restricted to venous thromboembolism but also can cause fetal loss (abortions or recurrent abortions and fetal demise), placental abruption, intrauterine growth restriction and severe preeclampsia. ${ }^{1-13}$ In the recent years various studies have 
evaluated the role of administering thromboprophylaxis to patients with previous history of adverse obstetric outcomes who have tested positive for inherited and acquired thrombophilia. ${ }^{11,14-17}$ This study adds to the existing data base discerning the role of thromboprophylaxis with heparin and ecosprin in patients with thrombophilia in pregnancy.

\section{METHODS}

Sixty antenatal patients aged between 20-35 years diagnosed with thrombophilia attending the antenatal clinic at large tertiary government - run teaching hospital were included in this study. Ethical clearence was obtained from the Standing Hospital Ethics Committe prior to commencement of the study.

\section{Inclusion Criteria}

All antenatal patients with singleton pregnancy with thrombophilia (inherited or acquired or both) with a history of previous adverse pregnancy outcomes were included in the study. Previous adverse pregnancy outcomes in the patients included in this study were defined as unexplained intrauterine demise, abortions or recurrent abortions, history of early onset preeclampsia, intrauterine growth restriction, abruptio placenta, history of deep venous thrombosis and cerebro vascular accidents occuring in previous pregnancy.

\section{Exclusion criteria}

Patients without any risk factors or bad obsteric history, those with multiple pregnancies, gestational diabetes, hypothyroidism, abnormal uterine morphology and autoimmune diseases were excluded from this study.

A total of 60 patients with history of previous adverse pregnancy outcomes diagnosed with thrombophilia (acquired, inherited or both) were prophylactically administered low dose ecosprin with either unfractionated heparin (30 patients) or low molecular weight heparin (30 patients). Written informed consent was obtained from all patients included in this study. The dose of ecosprin used was $75 \mathrm{mg}$ administered orally once daily (OD) and that of unfractionated heparin (UFH) was 5000 IU given subcutaneously (s.c) twice daily (BD) and low molecular weight heparin (LMWH), enoxaparin $40 \quad \mathrm{mg}$ subcutaneously once daily.

Thromboprophylaxis with low-dose ecosprin and heparin was commenced on confirmation of pregnancy and continued in the antenatal period in all patients included in this study. Ecosprin was discontinued at 36 weeks period of gestation and heparin (UFH or LMWH) was ceased twenty-four hours prior to induction of labour (at around 39 weeks period of gestation) in all participants. Heparin was thereafter continued for 06 weeks postpartum in all patients. Feto-maternal evaluations were serially undertaken during the course of the study. These included complete haemogram and coagulation profile every four weeks, obstetric ultrasound with color doppler velocimetry at $16,20,24,28,32,36$ weeks for assessment of utero-placental blood flow, fetal weight gain and fetal well-being. All pregnancies were closely followed-up and the obstetrical outcome was determined.

\section{Outcome measures}

The primary outcome measure was defined as: pregnancy outcome categorised as live (term or preterm) or still births. The secondary outcome measures included were: incidence of pregnancy associated complications such as intra-uterine growth retardation (IUGR), pre-eclampsia, abruptio placenta or a combination of both; thromboembolic events - deep vein thrombosis, pulmonary embolism, stroke, transient ischemic attack; the route of delivery - vaginal/caesarean delivery; potential side effects of antithrombotic therapy.

\section{Laboratory testing}

Blood samples were collected into vacuum tubes containing $3.8 \%(\mathrm{w} / \mathrm{v})$, sodium citrate as coagulant. The various tests used for confirming the diagnosis of thrombophilia in patients included in this study were as follows: Acquired thrombophilia:

- Anti-cardiolipin antibodies (ACA) - by ELISA technique, expressed as ACA IgG, ACA - IgM.

- Lupus anticoagulant - tested by Kaolin clotting time as screening test and ELISA technique.

Inherited thrombophilia: Samples were analyzed in a fully automated coagulometer (Stago) for inherited thrombophilia. Tested by determining Protein C, Protein $\mathrm{S}$, APCR, antithrombin III and homocysteine levels by ELISA technique in this study .

\section{Statistical methods}

The statistical analysis was done using Student's ' $t$ ' test and Chi square analysis with $\mathrm{p}$ value $<0.05$ taken as statistically significant.

\section{RESULT}

The distribution of patients who were investigated for pregnancy losses and found to have either congenital thrombophilia or acquired thrombophilia or both during the present pregnancy is as shown in Table 1.

In this study, $23.33 \%$ cases tested positive for inherited thrombophilia, $70 \%$ cases were positive for acquired thrombophilia and $6.67 \%$ were positive for combined acquired and inherited thrombophilia. Highest percentage of patients were found to have acquired thrombophilia as causative factor for previous pregnancy losses in this study. 
Table 1: Correlation of pregnancy losses in previous pregnancies with type of thrombophilia in this study.

\begin{tabular}{|c|c|c|c|c|c|c|c|c|}
\hline \multirow{2}{*}{$\begin{array}{l}\text { No. of adverse } \\
\text { pregnancy } \\
\text { outcomes in } \\
\text { previous } \\
\text { pregnancy }\end{array}$} & \multicolumn{2}{|c|}{$\begin{array}{l}\text { Inherited } \\
\text { thrombophilia }\end{array}$} & \multicolumn{2}{|c|}{$\begin{array}{l}\text { Acquired } \\
\text { thrombophilia }\end{array}$} & \multicolumn{2}{|c|}{$\begin{array}{l}\text { Combined inherited } \\
\text { and acquired } \\
\text { thrombophilia }\end{array}$} & \multicolumn{2}{|l|}{ Total } \\
\hline & $\begin{array}{l}\text { No. of } \\
\text { cases }\end{array}$ & $\%$ & $\begin{array}{l}\text { No. of } \\
\text { cases }\end{array}$ & $\%$ & $\begin{array}{l}\text { No. of } \\
\text { cases }\end{array}$ & $\%$ & $\begin{array}{l}\text { No. of } \\
\text { cases }\end{array}$ & $\%$ \\
\hline 1 & 0 & $(0)$ & 9 & $(15)$ & 0 & $(0)$ & 9 & $(15)$ \\
\hline 2 & 11 & (18.33) & 17 & (28.33) & 3 & (5) & 31 & (51.67) \\
\hline 3 & 3 & $(5)$ & 12 & $(20)$ & 1 & $(1.67)$ & 16 & $(26.67)$ \\
\hline$\geq 4$ & 0 & $(0)$ & 4 & $(6.67)$ & 0 & (0) & 4 & $(6.67)$ \\
\hline Total & 14 & $(23.33)$ & 42 & $(70)$ & 4 & (6.67) & 60 & $(100)$ \\
\hline
\end{tabular}

Table 2: Obstetric outcomes of previous untreated pregnancies and the present treated pregnancy in this study.

\begin{tabular}{|c|c|c|c|c|c|c|}
\hline \multirow{3}{*}{$\begin{array}{l}\text { Pregnancy } \\
\text { losses and live } \\
\text { births }\end{array}$} & \multicolumn{6}{|l|}{ Pregnancies } \\
\hline & \multicolumn{2}{|c|}{ Untreated (previous) $(n=151)$} & \multicolumn{2}{|c|}{ Treated $($ present $)(n=60)$} & \multirow[t]{2}{*}{$\chi^{2}$ test } & \multirow[t]{2}{*}{ 'P' Value } \\
\hline & No. of cases & $\%$ & No. of cases & $\%$ & & \\
\hline $\begin{array}{l}\text { 1stTrimester } \\
\text { pregnancy losses }\end{array}$ & 113 & $(74.83)$ & 0 & $(0)$ & 93.68 & $<0.0001$ \\
\hline $\begin{array}{l}\text { Pregnancy losses } \\
\text { (in } 2^{\text {nd }} \text { and } 3^{\text {rd }} \\
\text { Trimester) }\end{array}$ & 23 & $(15.23)$ & 1 & (1.67) & 6.55 & $<0.01$ \\
\hline Live births & 15 & $(9.93)$ & 59 & $(98.33)$ & 151.26 & $<0.0001$ \\
\hline
\end{tabular}

Patients were treated with low-dose ecosprin (75 mg OD, orally) and injection heparin (UFH, 5000 IU,BD or enoxaparin $40 \mathrm{mg}$, OD) subcutaneously in the present pregnancy.

When the outcome of previous untreated pregnancies is compared to that of the present treated pregnancies, the positive obstetric outcome with therapy is evident (Table 2). Amongst the 60 patients included in present study who received thromboprophylaxis with ecosprin and heparin, 59 patients had a live birth $(98.33 \%$; p <0.0001) which is statistically highly significant. None of the patients included in this study received therapy with ecosprin and heparin in previous pregnancies.

Table 3: Pregnancy outcomes in patients with thrombophilia receiving thrombophylaxis with ecosprin and heparin during pregnancy.

\begin{tabular}{|c|c|c|c|c|c|c|c|}
\hline \multicolumn{6}{|c|}{ Pregnancy outcome } & \multirow{2}{*}{\multicolumn{2}{|c|}{ Total }} \\
\hline Preterm & & Term & & Abortion & & & \\
\hline No. of cases & $\%$ & No. of cases & $\%$ & No. of cases & $\%$ & No. of cases & $\%$ \\
\hline $1 \quad(1.67)$ & & 58 & (96.66) & 1 & (1.67) & 60 & (100) \\
\hline
\end{tabular}

$\chi^{2}=2, \mathrm{P}<0.05$

Table 4: Distribution of obstetric complications in patients with thrombophilia who received thromboprophylaxis in pregnancy.

\begin{tabular}{|lll|}
\hline Obstetric complication & No. of cases & $\%$ \\
\hline Gestational hypertension & 5 & 8.33 \\
\hline $\begin{array}{l}\text { Intrauterine Growth Restriction } \\
\text { (IUGR) }\end{array}$ & 4 & 6.67 \\
$\begin{array}{l}\text { Gestational hypertension } \\
\text { +intrauterine growth restriction }\end{array}$ & 3 & 5 \\
\hline Total & 14 & (23.33) \\
\hline
\end{tabular}

Fifth-eight of these patients who received thromboprophylaxis in the present pregnancy had term delivery, 01 patient had preterm delivery and 01 patient had abortion (live births 98.33\%; p <0.0001) (Table 3). Out of these 58 deliveries at term, 45 delivered vaginally, 13 were delivered by caesarean section at term and 01 underwent preterm caesarean section. The mean birth weight ranged between $2.4 \mathrm{~kg} \pm 0.29-2.69 \mathrm{~kg} \pm 0.30$.

Amongst the 60 patients included in the study, at total of 12 patients had obstetric complications during the course of the present pregnancy. Gestational hypertension occurred in 5 cases (8\%), Intrauterine Growth Restriction 
(IUGR) in 4 cases $(6.6 \%)$ and combination of both in 3 cases $(5 \%)$ (Table 4$)$.

\section{DISCUSSION}

Pregnancy is a thrombogenic state. It is this hypercoaguable condition that paves way to thrombotic events more often in pregnant population than in general population resulting in adverse outcomes like abortions or recurrent abortions, intraurine growth restriction, intrauterine fetal demise, placental abruption and preeclampsia. ${ }^{1-13}$ Hence, the evaluation and management of thrombophilia is imperative in women who have history of fetal loss/losses or adverse pregnancy outcomes.

Patients in our study group, with mean age of 21 to 25 years reflective of the prime reproductive age group, were evaluated for previous adverse pregnancy outcomes. It was revealed that $23.33 \%$ cases tested positive for inherited thrombophilia, $70 \%$ cases were diagnosed with acquired thrombophilia and $6.67 \%$ were positive for combined - acquired and inherited thrombophilia. The highest percentage of cases were found to have acquired thrombophilia as causative factor for previous pregnancy losses. These 60 patients with history of previous pregnancy losses who were diagnosed with thrombophilia in the present study were administered low dose ecosprin and heparin (either unfractionated or low molecular weight) from the time of confirmation of pregnancy and continued on the same throughout the period of gestation. The overall percentage of live births in our study group was significantly higher after treatment with heparin and ecosprin (live birth\% - 98.33\%; $\mathrm{p}<0.0001$ ). This supports the contention that administration of heparin and ecosprin improve obstetric outcomes in patients with thrombophilia. $^{11,14-17}$

Studies conducted in the past have highlighted the increase in live birth rates after thromboprophylaxis in pregnancy with thrombophilia. ${ }^{18-21}$ A study by Carp $\mathrm{H}$ et al. ${ }^{(18)}$ (2003) in patients with inherited thrombophilia 26 of the 37 pregnancies in treated patients $(70.2 \%)$ resulted in live births, compared with 21 of $48(43.8 \%)$ in untreated patients $(\mathrm{P}<0.02$, OR 3.03, 95\% CI 1.12-8.36) after thromboprophylaxis. Michael J Kupferminc (2003) pointed out that there was $14 \%$ reduction in fetal and/or neonatal death and reiterated that the combination of aspirin and heparin is effective in recurrent fetal loss in APS syndrome and could be considered for women with inherited thrombophilias and history of severe preeclampsia, IUGR, abruptio placentae or fetal loss. Brenner B et al (2003) found to have (75\%) live births after therapy compared to $20 \%$ in previous pregnancies without antithrombotic therapy. Kupferminc MJ et al. ${ }^{19-21}$ (2011) stated increased risk of adverse pregnancy outcome in patients with thrombophilia, but also concluded that heparin was beneficial as a treatment and prevention and resulting in live birth rates. Similarly, our study group which includes inherited, acquired and combination of both inherited and acquired thrombophilia also reveals significantly higher live births with therapy (live birth\% - 98.33\%; p <0.0001).

Various randomised control trials recommend administration of low dose ecosprin and heparin for treatment of pregnant women with Antiphospholipid Antibody (APLA) syndrome. ${ }^{11,16,22-24}$ The benefit of the same treatment protocol as used in APLA syndrome is under evaluation for treatment of pregnant women with inherited thrombophilia. A few small uncontrolled trials or observational studies do favour antithrombotic therapy and ecosprin in pregnancies with inherited thrombophilia. ${ }^{18,21,25-27}$ However, the recommendation of antithrombotic therapy and ecosprin as a therapeutic option in pregnancy with inherited thrombophilia is still awaited for paucity of randomised control trials. In our study group, patients with either acquired or inherited thrombophilia had live births after treatment with heparin and ecosprin (live birth \% $-98.33 \% ; \mathrm{p}<0.0001$ ).

Placental vascular complications like intrauterine growth restriction, preeclampsia or both, abruptio placenta were monitored during pregnancy in our study. It was found that despite the treatment, amongst 60 patients included in our study group, 12 patients had antepartum complications of which 04 patients were diagnosed with intrauterine growth restriction, 05 patients gestational hypertension and 03 patients had combination of both. These patients were also aggressively monitored at regular intervals and resulted in live births. Following our treatment protocol no case of abruptio placenta, fetal or neonatal demise was observed. There was no instance of thromboembolic events such as deep vein thrombosis, pulmonary embolism, stroke, transient ischemic attack or heparin induced thrombocytopenia (HIT) in this study.

The authors acknowledge that due to the relatively small sample size of 60 patients used, the study may be inadequately powered to unequivocally establish the full impact of therapeutic measures undertaken on the obstetric outcomes in this study. Nevertheless, this study adds to the existing database and could be the precursor of further research in this field towards formulation of larger, multi-centric randomized controlled trials in future.

\section{CONCLUSION}

Present study reveals that prophylaxis with low dose ecosprin and heparin administered to patients with thrombophilia with history of previous recurrent pregnancy losses resulted in a significantly improved obstetric outcome in terms of a significantly higher number of live births. This study confirms that a definite role of thromboprophylaxis exists in the management of pregnancies with acquired thrombophilia and suggests its plausible role in those with inherited thrombophilia. Larger, multicentre trials and definitive guidelines are needed to further elaborate on the role of 
thromboprophylaxis in pregnancies with inherited thrombophilia.

Funding: No funding sources

Conflict of interest: None declared

Ethical approval: The study was approved by the Institutional Ethics Committee

\section{REFERENCES}

1. Alfirevic Z, Roberts D, Martlew V. How strong is the association between maternal thrombophilia and adverse pregnancy outcome. A systematic review. Eur J Obstet Gynecol Reprod Biol. 2002;101:6-14.

2. Rey E, Kahn SR, David M, Shrier I. Thrombophilic disorders and fetal loss: a meta-analysis. The Lancet. 2003 Mar 15;361(9361):901-8.

3. Kujovich JL. Thrombophilia and pregnancy complications. Am J Obstet Gynecol. 2004;191:41224.

4. Robertson L, Wuo, Langhome P, Twaddle S, Clark P, Lowe GD et al. Thrombophilia in pregnancy: a systematic review. Br J Haematol. 2006;132 (2):17196.

5. Middeldorp S. Thrombophilia and pregnancy complications: cause or association $\mathrm{J}$ Thromb Haemost. 2007; 5 Suppl 1:276-282.

6. Hossain N, Paidas MJ. Adverse pregnancy outcome, the uteroplacental interface, and preventive strategies, seminars in perinatology. Perintolol. 2007;31(4):208-12.

7. Vora S, Shetty S, Ghosh K. Thrombophilic dimension of recurrent fetal loss in Indian patients. Blood Coagul Fibrinolysis. 2008;19:581-4.

8. Pabinger I. Thrombophilia and its impact on pregnancy11Adapted from Pabinger I, Thrombophilia and its impact on pregnancy, Hamostaseologie. 2008;28(3):130-4.

9. Mishra MN, Bedi VS. Prevalence of common thrombophilia markers and risk factors in Indian patients with primary venous thrombosis. Sao Paulo Med J. 2010;128(5):263-7.

10. Hansda J, Roychowdhury J. Study of thrombophilia in recurrent pregnancy loss. J Obstet Gynecol India. 2012;62:536-40.

11. Bennett SA, Bagot CN, Arya R. Pregnancy loss and thrombophilia: the elusive link. $\mathrm{Br} \mathrm{J}$ Hematol. 2012;157(5):529-42.

12. American College of Obstetricians and Gynecologists: Practice Bulletin No. 138: Inherited thrombophilias in pregnancy. Obstet Gynecol. 2013;122(3):706-17.

13. Simcox LE, Ormesher L, Tower C, Greer 1A. Thrombophilia and pregnancy complications. Int $\mathrm{J}$ Mol Sci. 2015;16(12):28418-28.

14. Kher A, Bauersachs R, Nielsen JD. The management of thrombosis in pregnancy: role of LMWH. Thromb Haemostat. 2007;97(4):505-13.
15. James A, Committee on Practice BulletinsObstetrics. Practice bulletin no. 123: thromboembolism in pregnancy. Obstet Gynecol. 2011 Sep;118(3):718-29.

16. Bates SM, Greer IA, Middledorp S, Veenstra DL, Prabulos AM, Vandvik PO. VTE, thrombophilia, antithrombotic therapy, and pregnancy: Antithrombotic Therapy and Prevention of Thrombosis, 9th ed: American College of Chest Physicians Evidence-Based Clinical Practice Guidelines. Chest. 2012 Feb;141(2 Suppl):e691Se736S.

17. Lockwood CJ. Thrombosis, thrombophilia and thromboembolism. American College of Obstetricians and Gynecologists; 2007.

18. Carp H, Dolitzky M, Inbal A. Thromboprophylaxis improves the live birth rate in women with consecutive recurrent miscarriages and hereditary thrombophilia. J Thromb Haemost. 2003;1:433-8.

19. Kupferminc MJ. Thrombophilia and pregnancy. Reprod Biol Endocrinol. 2003;1:111.

20. Brenner B. Antithrombotic prophylaxis for women with thrombophilia and pregnancy complications-Yes. J Thromb Haemost. 2003;1:2070-2.

21. Kupferminc MJ, Rimon E, Many A, Sharon M, Lessing JB, Gamzu R.. Low molecular weight heparin treatment during subsequent pregnancies of women with inherited thrombophilia and previous severe pregnancy complications. J Matern Fetal Neonatal Med. 2011;24:1042-5.

22. American College of Obstetricians and Gynecologists: Practice Bulletin No. 132: antiphospholipid syndrome. Obstet Gynecol. 2012;120(6):1514-21.

23. McNamee K, Dawood F, Farquharson R. Recurrent miscarriage and thrombophilia: an update. Curr Opin Obstet Gynecol. 2012;24:229-34.

24. Battinelli EM, Marshall A, Connors JM. The role of thrombophilia in pregnancy. Thrombosis. $2013 \mathrm{Dec}$ $18 ; 2013$.

25. Lockwood CJ. Inherited thrombophilias in pregnant patients: detection and treatment paradigm 1, 2 . Obstet Gynecol. 2002 Feb 28;99(2):333-41.

26. De Carolis S, Ferrazzani S, De Stefano V, Garofalo $\mathrm{S}$, Fatigante G, Rossi $\mathrm{E}$ et al. Inherited thrombophilia: treatment during pregnancy. Fetal Diagnosis Therapy. 2006;21(3):281-6.

27. Folkeringa N, Brouwer JL, Korteweg FJ, Veeger NJ, Erwich JJ, Holm JP et al. Reduction of high fetal loss rate by anticoagulant treatment during pregnancy in antithrombin, protein $\mathrm{C}$ or protein $\mathrm{S}$ deficient women. Br J Haematol. 2007:1;136(4):656-61.

Cite this article as: Asthana S, Sodhi B, Kumar S. Role of low dose ecosprin and heparin in achieving live births in pregnancy with thrombophilia. Int J Reprod Contracept Obstet Gynecol 2017;6: 5261-5. 